\title{
Simulation of Laboratory Hydrate Loop Using Aspen Hysys
}

\author{
Odutola Toyin Olabisi ${ }^{1, ~ *, ~ U g w u ~ C h u k w u e m e k a ~ E m m a n u e l ~}{ }^{2}$ \\ ${ }^{1}$ Department of Petroleum and Gas Engineering, University of Port Harcourt, Rivers State, Nigeria \\ ${ }^{2}$ Department of Chemical Engineering, University of Port Harcourt, Rivers State, Nigeria
}

Email address:

toyin.odutola@uniport.edu.ng (O. T. Olabisi),coolmechel@gmail.com(U. C. Emmanuel)

${ }^{*}$ Corresponding author

\section{To cite this article:}

Odutola Toyin Olabisi, Ugwu Chukwuemeka Emmanuel. Simulation of Laboratory Hydrate Loop Using Aspen Hysys. Engineering and Applied Sciences. Vol. 4, No. 3, 2019, pp. 52-58. doi: 10.11648/j.eas.20190403.11

Received: April 12, 2019; Accepted: June 23, 2019; Published: July 4, 2019

\begin{abstract}
Gas hydrates have repeatedly plagued the oil and gas industry by impeding flow and causing catastrophic damages to subsea pipelines and equipment. Several software as well as equipment have been developed to reduce hydrate plugs in the field. In this study, steady state simulation and dynamic state simulation on a laboratory hydrate loop was carried out using Aspen Hysys. During the simulation, two mixers (Mixer 1 and Mixer 2) were selected to create the inhibitor water stream and the mixed feed stream respectively in the Process Flow Diagram (PFD). A pump was then selected to boost the pressure in the simulation to $150 \mathrm{psia}$ and to agitate the fluid. Heat exchanger was selected to reduce the temperature to hydrate formation temperature, mimicking the action of the 4" PVC water bath in which the loop is immersed in the experimental set up. In the dynamic simulation, valves were included in the feed stream of the PFD created for the steady state simulation. The feed stream used in the simulation study contained $85 \%$ methane and $2 \mathrm{wt} \%$ methanol as inhibitor. The steady state simulation did not record hydrate formation implying that the $2 \mathrm{wt} \%$ Methanol used as inhibitor was sufficient to prevent hydrate formation in the loop. However, the dynamic state simulation which was set to run for 2 hours just as the experimental setup recorded hydrate formation at a temperature of $4.26{ }^{\circ} \mathrm{C}$ and a pressure of $83.84 \mathrm{psi}$. This can also imply that during shut in process, hydrate formation may not occur as the line may only attain hydrate formation temperature. However, during restart prrocess which is like the dynamkic simulation, a lot of aggitation takes place and hydrate formation will be noticed. Therefore, the engineer must proceed to dynamic state simulation before concluding on the effectiveness of a particular dosage of inhibitor prior to field application.
\end{abstract}

Keywords: Gas Hydrate, Laboratory Hydrate Loop, Flow Assurance, Hydrate Inhibition, Hydrate Prediction

\section{Introduction}

Gas hydrate is a solid ice-like form of water that contains gas molecules in its molecular cavities. Sequel to the discovery of natural gas hydrate formation in gas transmission systems by Hammerschmidt in 1934, various investigations on hydrates have established the nature of hydrate in multicomponent mixtures of hydrocarbons and water and the effects of gases such as $\mathrm{H}_{2}, \mathrm{CO}_{2}, \mathrm{~N}_{2}$ and $\mathrm{H}_{2} \mathrm{~S}$ on hydrate formation in hydrocarbon gases. Several methods for predicting hydrate formation in pure and multi component hydrocarbon gas systems have also been developed.

Hydrates are known to form in at least three crystal structures (Type I, Type II, and Type H) depending upon the hydrate formers in the mixtures, the temperature and the pressure [1]. Other essential conditions for gas hydrate formation include: favourable conditions of pressure and temperature of the gas, presence of liquid water phase and thorough agitation between the phases

Hydrate has caused remarkable increase in costs of production due to the cost of hydrate inhibitors especially offshore [2]. Hydrates have reduced production in subsea flowlines carrying wet gas, and in cold-weather operations by clogging these lines and reducing throughput. In advent of a plugged flowline, shipping becomes the only source of transporting the product, thus increasing transportation cost. The clogged line may further aggravate and cause complete shutdown of the system, leading to massive loss of revenue. Hydrate formation also causes increased maintenance and subsequent replacement of pneumatic pumps used in pumping inhibitor into the flowlines [3]. It may also increase corrosion rates resulting from the various substances employed to 
counter hydrate formation and its associated problem.

Hydrates can be prevented by the use of thermodynamic hydrate inhibitors (THI) consisting of salts and glycols [4], use of surfactants called anti agglomerates (AA) [5*], and use of polymers known as Kinetic Hydrate Inhibitors (KHI) [6]. Other methods of managing gas hydrates include heating gas above hydrate formation temperature, Pigging [7], thermal insulation [8] and electrical heating [9]. Hydrates can also be prevented by the use of the low temperature separation process (LTX) which purposely forms hydrates by Joule-Thompson expansion, separates them from the cold gas, moves them to a warm zone, thereby decomposing hydrates into hydrocarbons and water [10].

Researchers have developed several software such as Hysys to ease hydrate prediction and hydrate inhibitor selection. Hysys is a Hyprotech Systems process modeling software by AspenTech used for steady state simulation, design, performance monitoring, optimization and business planning for oil and gas production, gas processing and petroleum refining industries. Hysys has thermodynamic models embedded in it that aids in its ability to accurately predict the formation conditions for hydrate in flowlines using the Hysys Hydrate Formation Utility [11]. This Hydrate Formation utility in Hysys calculates the incipient solid formation point for hydrates [12]. The predictive models are based on fundamental thermodynamic principles and uses equation-of-state generated properties in calculating equilibrium conditions. These predictive models can be applied to various compositions, and extreme operating conditions with a greater degree of reliability than one may expect with empirical expressions or charts.

The only requirement for hydrate formation is that some water must be present in either the vapour or condensed hydrocarbon phase with hydrate forming components. Once favourable pressure and temperature conditions are reached (high pressures or low temperatures), the mixture of hydrate-forming molecules and water molecules form a non-stoichiometric solid phase. These favorable conditions can be well above the freezing point of water, or well before the point where free water or ice would drop out.

Models used for predicting the incipient hydrate point are generally based on the original hydrate equilibrium model proposed by Van der Waals and Platteeuw, coupled with a modification suggested by Parrish and Prausnitz [2]. These models have been incorporated and enhanced by AspenTech for its hydrate predictions. In addition, the equation of state is used to predict properties of the hydrate-forming components that are in equilibrium with the solid hydrate phase [13]. The hydrate prediction models used in Hysys are as follows: 2-Phase Model, 3-Phase Model, SH Model, and Assume Free Water Model.

This study simulates a hydrate equipment by Odutola et al [14] using Aspen Hysys and compares the experimental result with the result obtained from the simulation. The equipment is a 12 meters laboratory closed flow loop fabricated using 316 stainless steel pipe of 0.5 inch internal diameter, enclosed in an insulated 4inch Polyvinylchloride (PVC) pipe. The loop is skid mounted and fitted with 3 electric pumps, one manual pump, 5 temperature gauges, 8 pressure gauges, 2 differential pressure transmitters, a gas mixing vessel, an inhibitor mixing vessel, 3 valves and a Compressed Natural Gas (CNG) cylinder (Figure 1).
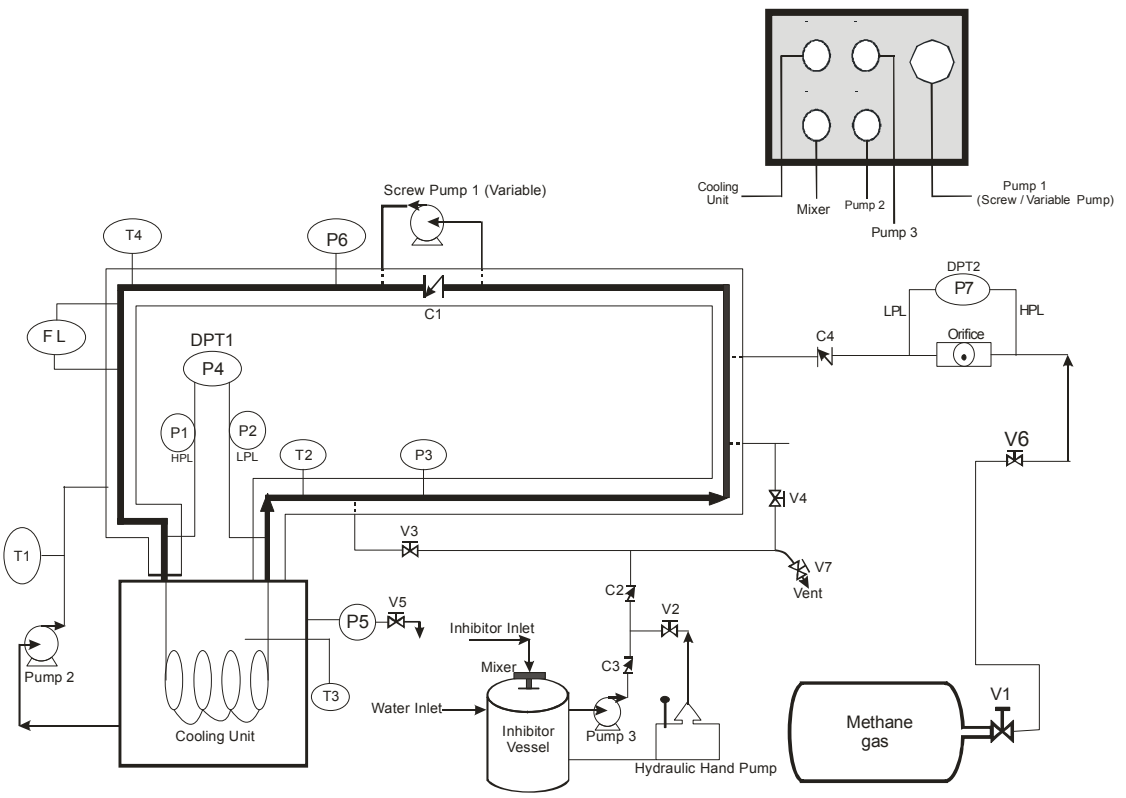

Figure 1. Process Flow Diagram of Hydrate Loop.

\section{Brief Description of the Hydrate Loop}

The laboratory loop is a 12 meters skid mounted closed loop fitted with valves, temperature guagues, pressure gauges, pumps, a high pressure gas cylinder, differential pressure transmitters as shown in the $3 \mathrm{D}$ model (Figure 2). The miniloop is modelled using AutoCAD plant 3D software. The front view, top view of and side view of the loop are also modelled. 


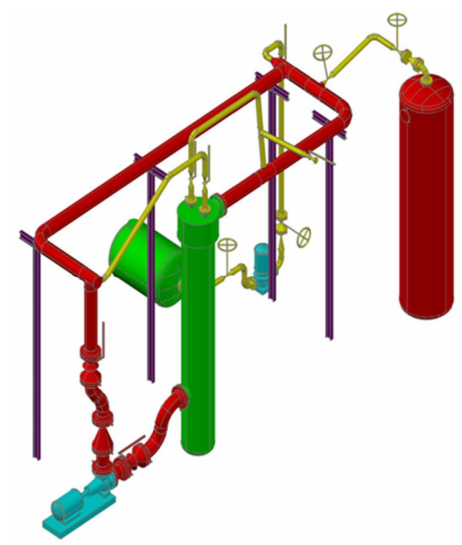

Figure 2. 3-D model of the Laboratory Hydrate loop.

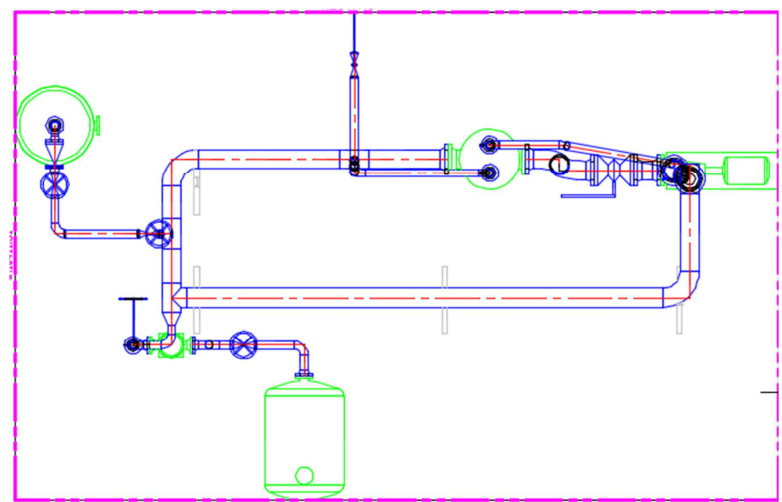

Figure 3. Top view of the $2 D$ model.

The top view of the loop (Figure 3) shows the circumference loop, the red broken line shows the 316 stainless steel pipe of 0.5 " diameter which represents the offshore flow line that is constantly immersed cold water contained in a 5" PVC enveloping the 316 stainless steel pipe. The refrigerator, gas cylinder and pumps can also be noticed from this view.

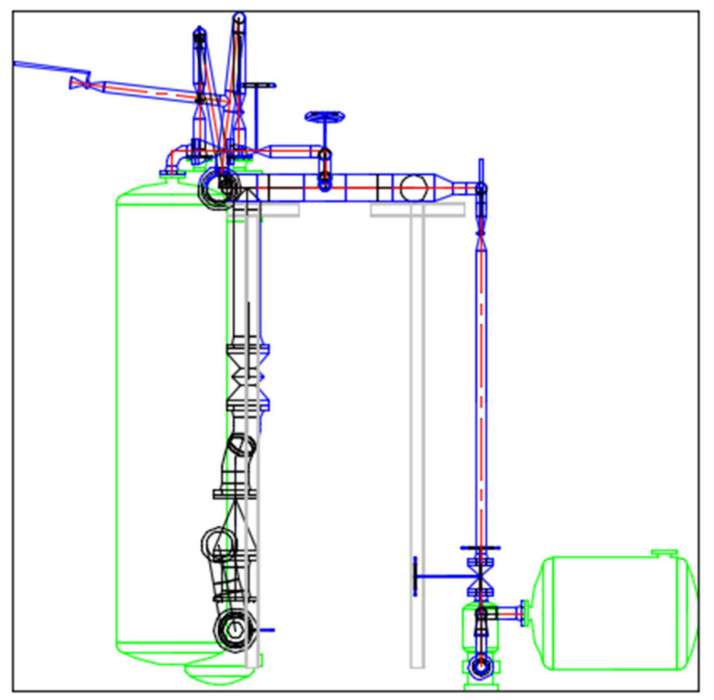

Figure 4. Side view of the $2 D$ model.

Figure 4 is the side view of the equipment. It shows the skid where the loop is mounted and also shows the connected high pressure cylinder and some valves and temperature and pressure gauges of the equipment.

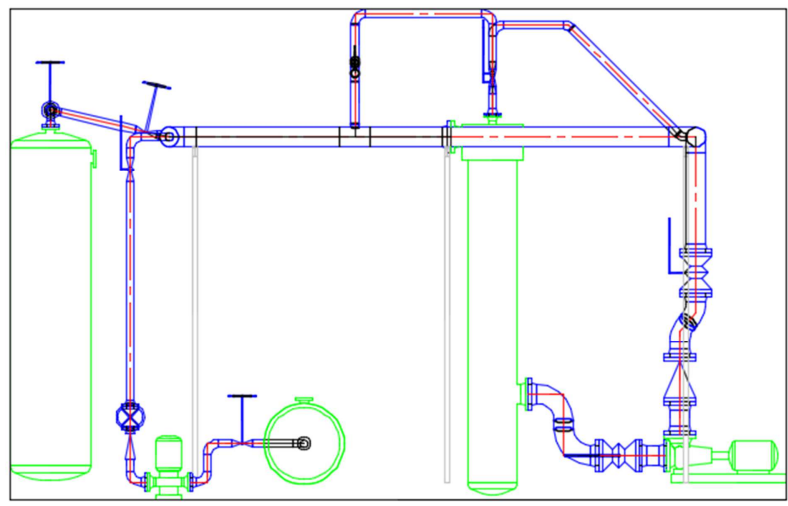

Figure 5. Front view of the $2 \mathrm{D}$ model.

Figure 5 shows the front view of the equipment. The skid mount is seen here as well as some pumps, water tank, cylinder and other fittings around the loop.

\section{Brief Description of the Experiment}

Materials used in the experiment are: $\mathrm{CNG}$ comprising of over $98 \%$ methane, water, ice for cooling, and $2 \mathrm{wt} \%$ methanol as hydrate inhibitor. During each experimental run, the loop was fed with about $435 \mathrm{ml}$ of water and methanol (98wt $\%$ water and $2 \mathrm{wt} \%$ methanol) to build the loop pressure to $25 \mathrm{psi}$. CNG is then injected into the loop through the orifice until the loop attains a pressure of $150 \mathrm{psi}$. The variable screw pump is turned on and set to a flow rate of $250 \mathrm{ft} \mathrm{hr}$. The screw pump provides agitation of gas and water fed into the loop. Ice is loaded into the refrigerator to speed up the cooling process as Pump 2 (Figure 1) is turned on to circulate cold water from the refrigerator. The 4 inch PVC pipe of the loop is lagged with fibre wool and Armaflex to prevent external influence of temperature in the system.

The experiment is conducted for 2 hours during which changes in the fluid in the loop is monitored from the pressure gauge, temperature gauges, and differential pressure meters. A drop in loop pressure is an indication of hydrate formation as some of the gas has been used up in forming hydrates. Also, an increase in temperature indicates hydrate formation because the hydrate formation is an exothermic reaction. A rise in differential pressure of the loop also indicates hydrate formation due to hydrate deposition on the internal walls of the 0.5 " pipe, causing a reduction in the internal diameter of the pipe.

\section{Hysys Simulation}

Steady state simulation and dynamic state simulation were carried out on the hysys model of the laboratory hydrate loop.

\subsection{Steady State Simulation}

The Hysys simulation performed on the loop was done based on the operating conditions of the Laboratory hydrate loop provided in Odutola et al [15]. The composition and 
conditions of the feed stream was keyed into the simulation basis manager as seen in Figure 6 while the inlet conditions were fed into Hysys using the simulation basis manager as seen in Figure 7.

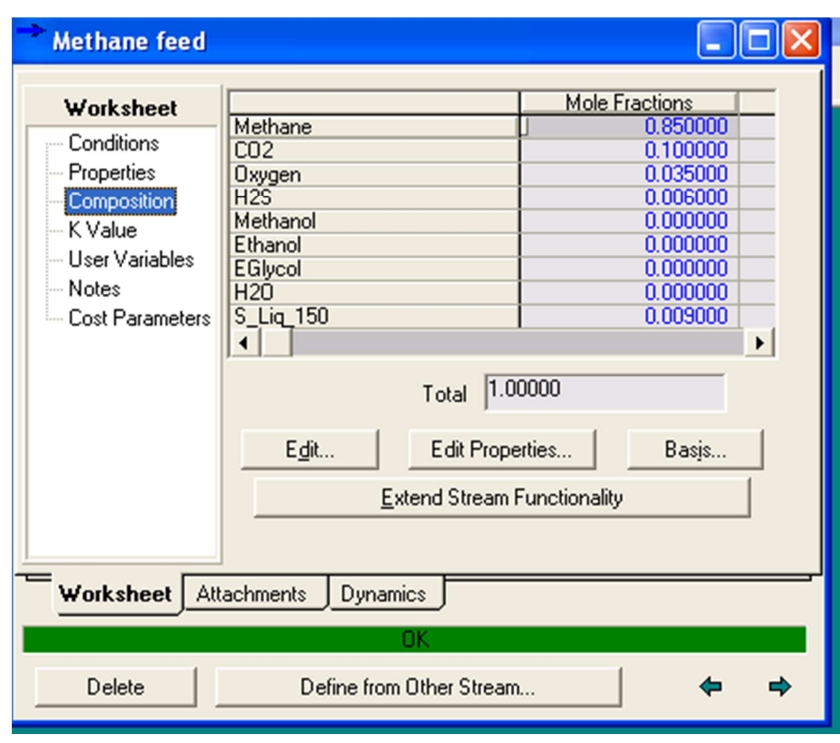

Figure 6. Composition of the Feed Stream.

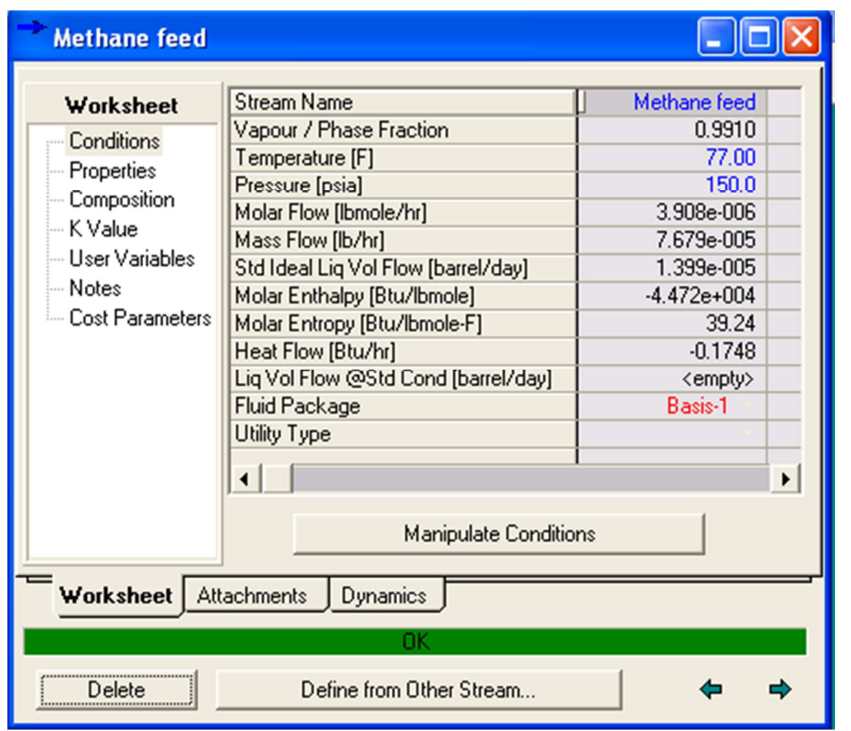

Figure 7. Inlet stream conditions.

The following conditions outlined below were used to obtain the steady state model of the laboratory hydrate flow loop (Figure 8):

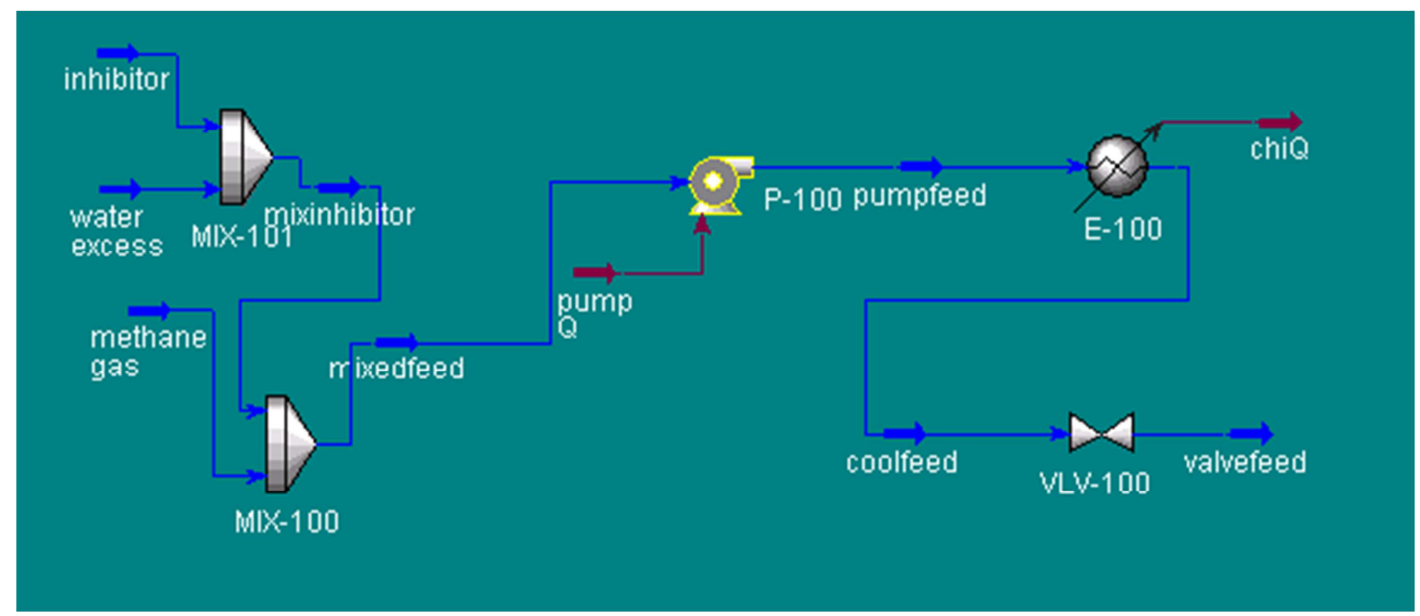

Figure 8. Steady state model of Laboratory Flow Loop.

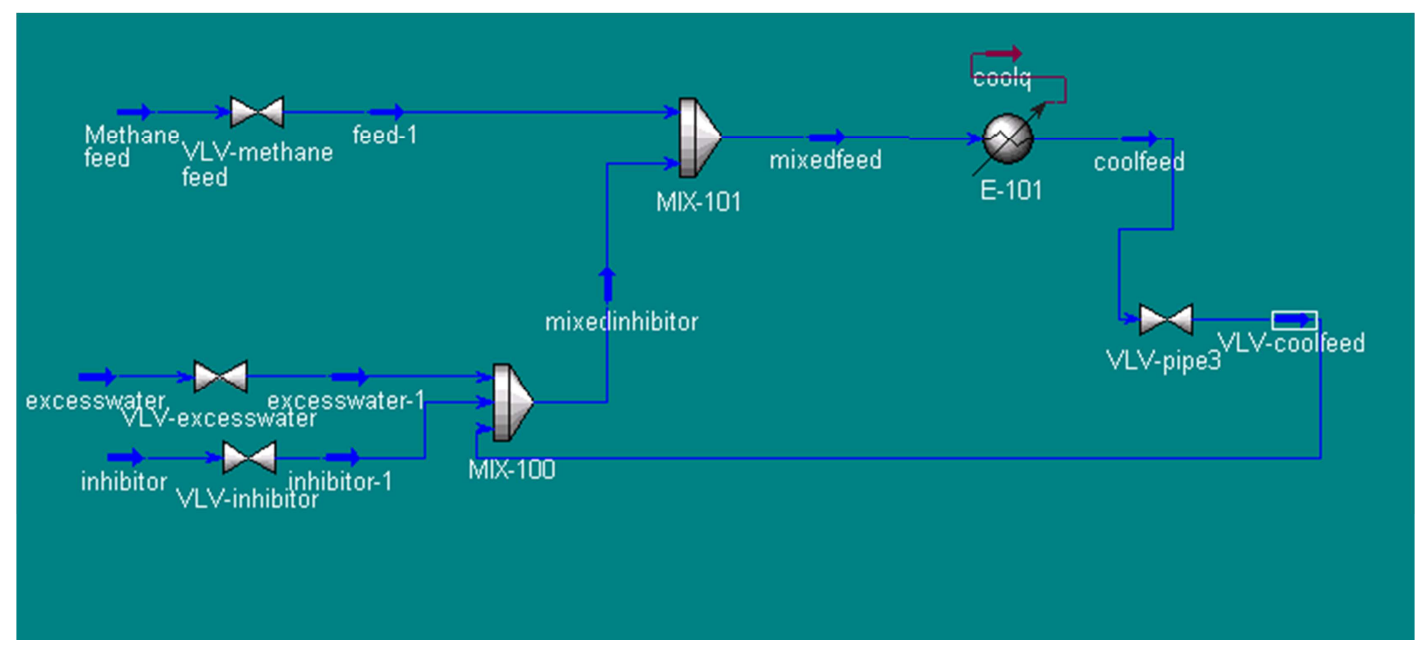

Figure 9. Dynamic state model of Laboratory Flow Loop. 
1. Mixer 1: this unit serves the purpose of mixing the inhibitor and excess water streams (2\% weight fraction of ethanol and $98 \%$ weight fraction of water) by equalizing their various pressures and giving out a single stream called mix-inhibitor. This stream is at a pressure of $25 \mathrm{psi}$ and temperature of $25^{\circ} \mathrm{C}$.

2. Mixer 2: the purpose of this unit is to mix the Compressed Natural Gas (CNG) with the mix-inhibitor stream before being introduced into the hydrate loop. The two streams mix together to form the mixed-feed stream. The two mixers serve the purpose of feed preparation.

3. Pump: this unit helps in elevating the mixed-feed stream pressure to about $150 \mathrm{psi}$ and it also serves as an agitator mimicking the action of the screw pump in the laboratory hydrate flow loop.

4. Heat exchanger: this unit is used to remove heat from the stream, representing the 4 inch PVC pipe containing cold water where the steel pipe is immersed in the loop. It is used to reduce the loop temperature to hydrate formation temperature.

Valve: this unit is used to control the outflow of streams from the loop, and this is the point where the hydrate formation is monitored having attained the operating condition of the loop.

\subsection{Dynamic State Operation}

The operating units for the steady state is the same for the dynamic state except for the inclusion of valves (Figure 9) both at the feed and product streams. The valves are called resistance. The resistance enables the Hysys integrator in the dynamic state to monitor and calculate how the pressure is varied with time which is a significant difference between the steady state and dynamic state of this model. In the dynamic state simulation, the operating conditions of temperature and pressure varies with time. A space time of two hours was used for this dynamic simulation to coincide with the duration of the experiments in the loop which is usually 2 hours.

\section{Results}

\subsection{Steady State Simulation Result}

In the steady state simulation, Hysys did not predict hydrate formation (Figure 10) at the given operating condition rather it predicted the formation of ice first (Figure 11). This is because there was no adequate agitation in the steady state model. This implies that although the temperature may reduce to hydrate formation temperature during shut in, hydrate formation may not occur due to reduced molecular integration between gas and water molecules.

Steady state simulation is for ideal circumstances as a result, the variation of pressure with time was not taken into consideration. This means that there was no pressure build up inside the loop during the simulation and hence the hydrate prediction indicated that ice was formed first at the given operating condition. The loop was unable to converge in the steady state as a result of continuous flow of material stream both at the feed and product end.

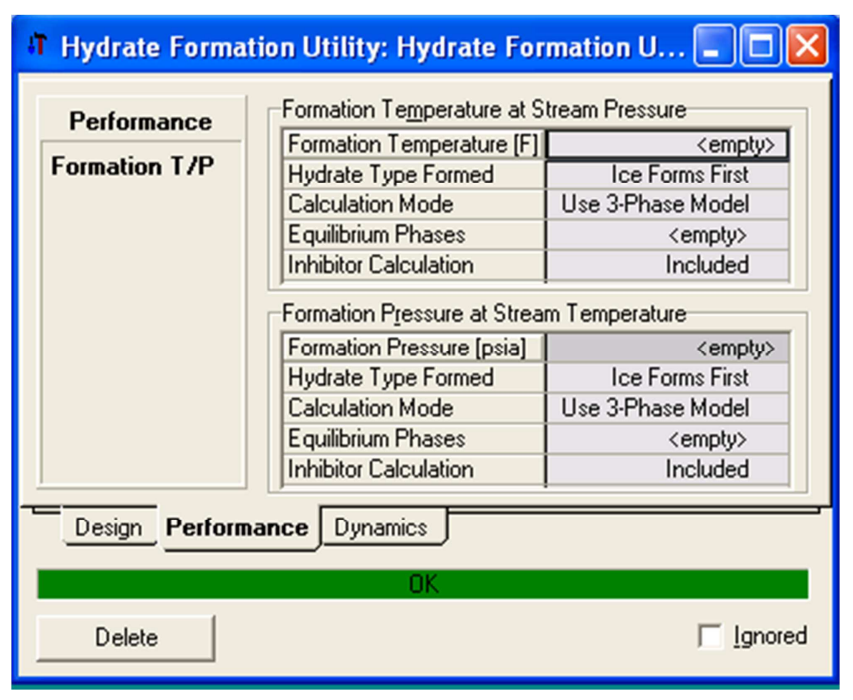

Figure 10. Hydrate Formation Utility Performance.

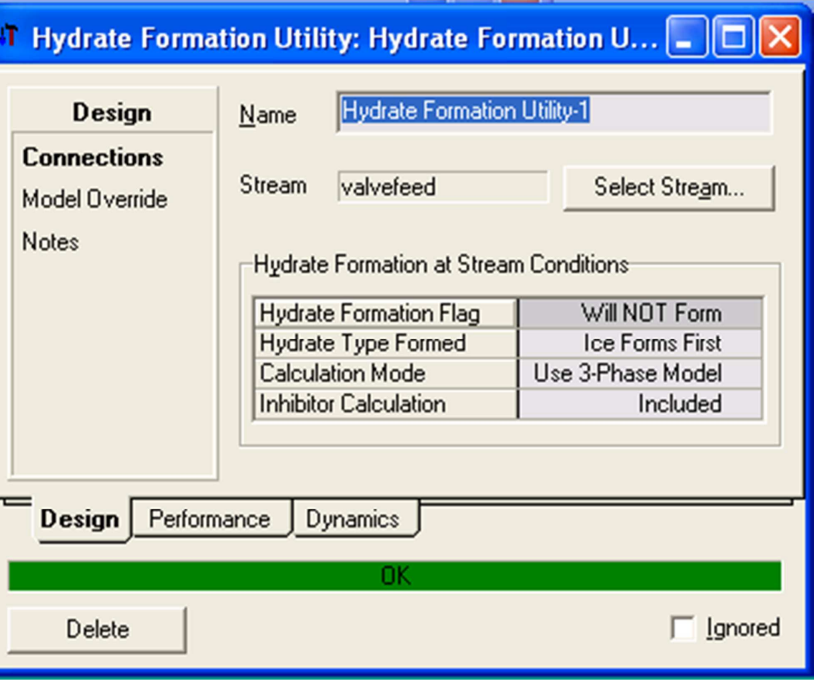

Figure 11. Hydrate Formation Utility Design Tab.

\subsection{Dynamic State Simulation Result}

In the dynamic state simulation, after 2 hours of running the integrator/solver, the hydrate forming flag indicated that Type I hydrate was formed (Figure 12) at a hydrate formation temperature of $4.26{ }^{\circ} \mathrm{C}$ and a hydrate formation pressure of 83.84 psi (Figure 13). This implies that agitation is necessary for hydrate formation. During shut down operations, the fluid attains hydrate formation temperature. When restart operation commences, the fluid is rapidly agitated and this causes hydrate formation to occur and subsequently, there can be a hydrate plug if hydrate formation is poorly managed.

Note that if the dynamic state simulation was not performed, it would have been assumed that the $2 \mathrm{wt} \%$ methanol used as inhibitor was adequate to prevent hydrate formation in the loop since the steady state simulation did not record hydrate 
formation. It is imperative that the dynamic simulation of the field is carried out especially when trying to choose the most appropriate inhibitor dosage.

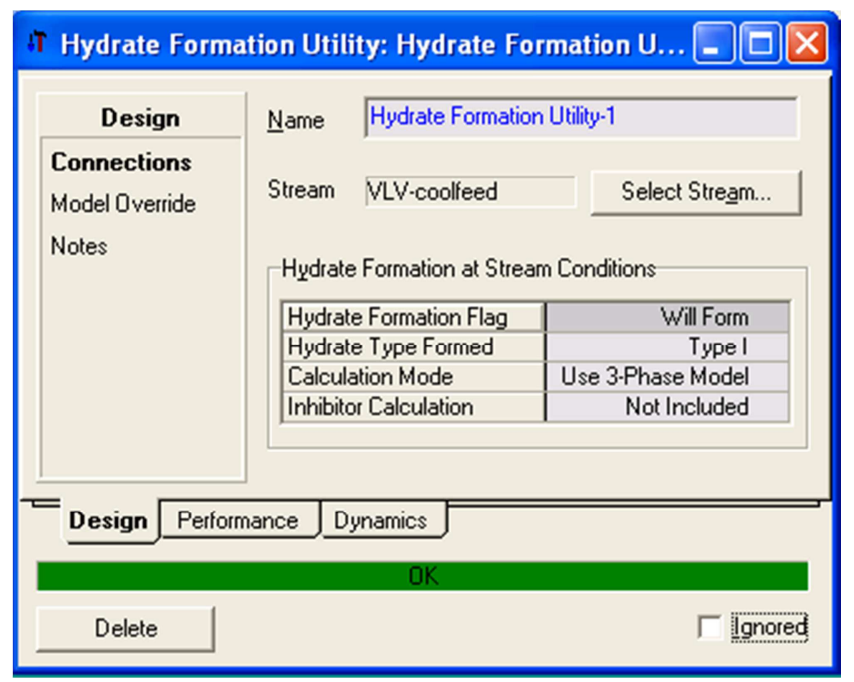

Figure 12. Hydrate Formation Utility Design Tab for Dynamic State Simulation.

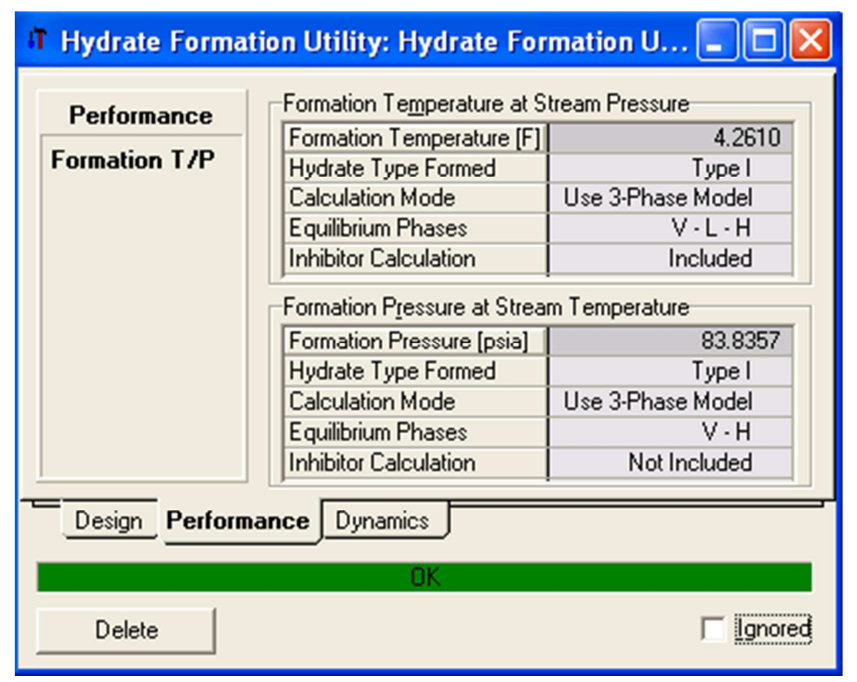

Figure 13. Hydrate Formation Utility Performance Tab for Dynamic State Simulation.

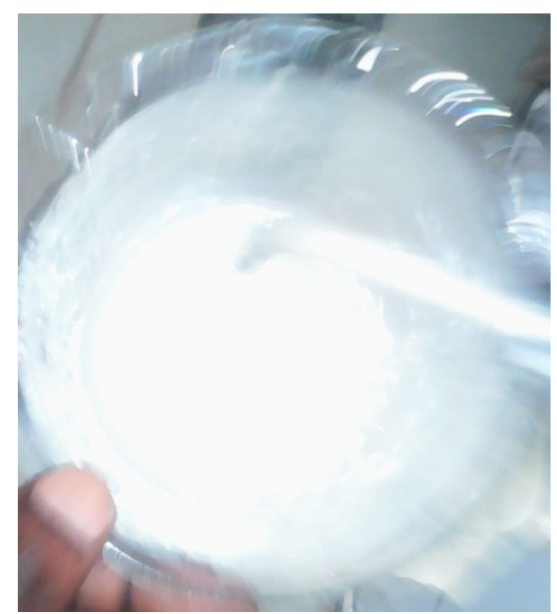

Figure 14. Effluent from $1 / 4$ inch tubing immediately after the experiment.
Experiment performed in the loop at similar conditions showed evidence of hydrate formation as the $1 / 4$ inch pipe connected to the refrigeration unit was partially plugged and the effluent from the pipe right after loop depressurization showed evidence of presence of hydrate crystals (Figure 14) that quickly dissociated to water and gas.

\section{Conclusion}

Aspen Hysys was able to adequately model the laboratory hydrate loop under study. It was observed that the steady state simulation did not give the true state of reaction in the loop as it predicted the absence of hydrate formation. However, the dynamic state simulation predicted the presence of hydrate formation in the loop just as occurred in the experiment conducted. This simulation can be used in predicting the outcome of experiments in the loop prior to carrying out the experiment. The simulation can also predict hydrate formation conditions which the loop is not currently equipped to do.

\section{References}

[1] Philips, N. J. \& Grainer, M., 1998. Development and application of kinetic hydrate inhibitors in the North sea. SPE Gas Technology Symposium, Issue 40030, pp. 398-404.

[2] Jardine, J. et al., 2014. History of Evolution of the Product Selection Criteria for Selecting Kinetic Hydrate Inhibitors. Malaysia, International Petroleum Technology Conference.

[3] Marathon, W. R., 1979. Gas Hydrate Control in Hostile Environment. Marathon oil company, pp. 1-4.

[4] A. P. Semenov, A. S. Stoporev, R. I. Mendgaziev, P. A. Gushchin, V. N. Khlebnikov, V. S. Yakushev, V. A. Istomin, D. V. Sergeeva, V. A. Vinokurov, Synergistic Effect of Salts and Methanol in Thermodynamic Inhibition of sII Gas Hydrates, J. Chem. Thermodynamics (2019), doi: https://doi.org/10.1016/j.jct. 2019.05.013

[5] Ballard A. L. and Sloan E. D. (2001): Hydrate phase diagrams for methane + ethane + propane mixtures. Chemical Engineering Science 56 (2001) 6883-6895.

[6] Mazlin I., Mazuin J., Faqrul N. Y., Wu P., Nasim K. (2018): "Preliminary study of natural polymer as kinetic hydrate inhibitor", Materials Today: Proceedings, Volume 5, Issue 10, Part 2, 2018, Pages 21667-21671, https://doi.org/10.1016/j.matpr.2018.07.017.

[7] Botrel, T., 2001. Hydrates Prevention and Removal in Ultra-deep Water Drilling Systems. OTC-12962-MS presented at Offshore Technology Conference, Houston, Texas.

[8] Owodunni, O. L., Ajienka, J. A., 2007. Use of Thermal Insulation to Prevent Hydrate and Paraffin Wax Deposition. SPE-111903-MS, Presented at the Nigeria Annual International Conference and Exhibition, 6e8 August, Abuja, Nigeria.

[9] Halvorsen, V. H., Lervik, J. K., Klevjer, G., 2000. Hydrate and Wax Prevention of Risers by Electrical Heating. ISOPE-I-00e118, presented at The Tenth International Offshore and Polar Engineering Conference, Seattle, Washington, USA. 
[10] Duncum, S., Edwards, A. R. \& Osborne, C. G., 1996. Trials of Threshold Hydrate inhibitors in the Ravensprun to Cleeton line. Society of Petroleum Engineers, pp. 250-255.

[11] Vasquez E. R., Eldredge T. (2011): "18 - Process modeling for hydrocarbon fuel conversion", Advances in Clean Hydrocarbon Fuel Processing, Science and Technology Woodhead Publishing Series in Energy, 2011, Pages 509-545, https://doi.org/10.1533/9780857093783.5.509.

[12] Davarnejad R., Jam A. and Jab A. (2014): "Prediction of Gas Hydrate Formation using Hysys Softtware (Technical Note)" IJE TRANSACTIONS C: Aspects Vol. 27, No. 9 (September 2014) $1325-1330$.

[13] Kvamme, B., 2001. Molecular Dynamics Simulations as a Tool for the Selection of Candidates for Kinetic Hydrate Inhibitors. Norway, The International Society of Offshore and Polar Engineers.

[14] Odutola T. O., Ajienka J. A., Onyekonwu M. O, Ikiensikimama S. S. (2017): "Design, Fabrication and Validation of a Laboratory Flow Loop for Hydrate Studies", American Journal of Chemical Engineering. Special Issue: Oil Field Chemicals and Petrochemicals, Volume 5, Issue 3-1, pp 28-41.

[15] Odutola T. O., Ajienka J. A., Onyekonwu M. O. and Ikiensikimama S. S. (2016): "Hydrate Inhibition in laboratory flowloop using polyvinylpyrrolidone, $\mathrm{N}$-Vinylcaprolactam and 2-(Dimethylamino) ethylmethacrylate" Journal of Natural Gas Science and Engineering, Volume 36, Part A, pp 54-61. 